\title{
HAJIM DAVIČO, TRADUCTOR Y CRÍTICO DE CERVANTES EN LAS LETRAS SERBIAS
}

En los últimos decenios de la centuria pasada, los judíos sefardíes radicados en Serbia empezaron a abandonar su tradicional aislamiento y a integrarse a la vida social circundante. Las primeras generaciones de intelectuales sefardíes se han formado con relativa rapidez; además de las instituciones religiosas, los jóvenes también cursaban estudios en escuelas superiores profanas. Así que, a finales del siglo XIX, un número considerable de abogados, políticos y funcionarios judíos - junto con médicos, comerciantes y banqueros, que por tradición eran israelitas- tomaban parte activa en la vida pública serbia.

Resultó que muchos de estos sefardíes eran buenos conocedores de la lengua y cultura de España, la patria que tuvieron que abandonar. De hecho, durante mucho tiempo, practicamente hasta bien entrado el siglo xx, el ladino seguía hablándose en el entorno familiar de muchos sefardíes balcánicos.

En este sentido, los hermanos Hajim y Benko Davičo fueron pioneros en la promoción de los valores espirituales hispánicos en nuestro país. Descendientes de una vieja familia judía de Belgrado, los Davičo, juristas de profesión los dos, también eran traductores del español y recopiladores del folklore sefardí. El hermano mayor, Hajim (1854-1916), pasó toda su vida profesional como alto funcionario y diplomático en varios ministerios del Reino de Serbia. Sin embargo, estaba muy presente en la vida cultural y artística de la capital serbia. Fue el primero en escribir cuentos con temática judía en nuestra literatura, y el primer autor hebreo que se realizó en idioma serbio ${ }^{1}$. Asimismo, gozó de mucho prestigio entre sus

\footnotetext{
1 Ha publicado dos libros de cuentos: Perla (1891) y Sa Jalije (1898).
} 
contemporáneos como crítico teatral y traductor de obras dramáticas de varias lenguas, entre las cuales destaca el español ${ }^{2}$.

Para nosotros reviste interés especial la dedicación cervantina de Davičo: ante todo, ha vertido al serbio dos textos dramáticos de Cervantes, por primera vez en nuestro idioma (se trata de los entremeses del "Juez de los divorcios» y del «Retablo de las maravillas»), y, luego, ha contribuido a la publicación de la primera traducción serbia del Quijote, en 1895-963.

El nombre de Hajim Davičo no figura en la portada de la traducción del Quijote hecha por nuestro primer traductor, Djordje Popović, llamado Daničar. No obstante, varias fuentes aseguran que este culto sefardí prestó ayuda al traductor en su labor ${ }^{4}$. Difícil de comprobar, esta afirmación, por lo menos, permite hacerse una idea de la reputación que tenía Davičo en la época: la de un raro especialista para todo lo referente a España, su cultura y su historia, su actualidad. Por otra parte, sí que se puede asegurar que Davičo ha seguido con interés la elaboración y la publicación del Quijote serbio. Sabemos que subrayó en diversas ocasiones la necesidad para nuestros lectores de tenerlo en su idioma, diciendo que «la carencia de esta traducción en nuestra literatura no ofrece buen testimonio de nuestro gusto literario" 5 .

Es harto probable que Davičo conociera a Djordje PopovićDaničar, y que los dos coincidieran en los mismos círculos literarios, sobre todo después de 1877, año en el que Popović se trasladó de Novi Sad a Belgrado. El sefardí, no cabe duda, admiraba a su colega mayor, que, además de traductor, fue periodista, escritor y lexicógrafo. Buena prueba de ello es la reseña de la traducción del Quijote, presentada a la Comisión de la Fundación Ilija Milosavljević Kolarac, futura editora del libro, como propuesta para su publicación, y firmada por Hajim Davičo y el crítico literario dr Ljubomir Nedić ${ }^{6}$ (en otro trabajo puntualizábamos que el autor es probable-

2 Ha traducido obras de Echegaray, Benavente, Rodríguez Rubí, Tamayo y Baus, Angel Guimerá, Hartzenbusch y el Duque de Rivas.

3 Migela de Servantesa Savedre, Veleumni plemić Don Kihote od Manče. Traducción del español DJoRdJE Popović. Fundación I. M. Kolarac. Beograd, 18951896, 4 vols.

4 AndJelija Popov, en el prólogo de una edición escolar del Quijote («Miguel de Servantes Saavedra, 1547-1616». In Miguel De Servantes: Don Kihot. Traducción Du. Popović, editora A. Popov. Znanje, Beograd, 1953, p. 27, y también DimitriJe VučEnov en su libro sobre Radoje Domanović, escritor serbio que conocía a Hajim Davičo (Radoje Domanović. Rad, Beograd, 1959, p. 147).

5 «dosadanja oskudica takoga prevoda u našoj književnosti, ne daje povoljnu svedodžbu o našem literarnom ukusu». HAIM DAVIčo, dr LJUBOMIR NEDIć: «O srpskom prevodu Don Kihota». Bosanska vila, 1896, 4, p. 62.

6 Ídem, pp. 62-63. 
mente Davičo) ${ }^{7}$. Aunque en el texto en cuestión se trata ante todo de la novela cervantina y de las condiciones que han generado su creación, y muy poco de la propia traducción - a ella se refieren tan sólo dos oraciones- el juicio formulado sobre los resultados del arte traductorio de Popović es muy positivo. Por desgracia, la reseña carece en absoluto de argumentos que la apoyarían y convencerían a los lectores que la versión de Popović es, como se afirma, «quizás la traducción más fiel del Quijote en el mundo» ${ }^{8}$.

Davičo se nos presenta como admirador fervoroso, e incluso exagerado, de Cervantes y de su obra, a la que llama «novela sobre las novelas» y «joya de la literatura castellana» (p. 63). Su impulso crítico no es muy profundo: se limita a una serie de consideraciones generales sobre Don Quijote, expresadas un sinfín de veces a lo largo del siglo XIX. Se inicia el texto con la tesis de la universalidad y la gran difusión del libro cervantino en el mundo, mientras la parte central está dedicada a las condiciones histórico-literarias en la España de Cervantes y en la inmediatamente anterior, en un intento de explicar la génesis de las novelas de caballerías. Los reseñadores hablan de Cervantes como de un hombre que "sin amparo, desgraciado como Job», creó una "sátira, más aguda que cualquier espada afilada» (p. 63), con la que ha conseguido derrumbar el antiguo mundo espiritual engendrado por la imaginación enferma de los viejos escritores. De lo que sigue se deduce que Davičo y Nedić, por su valor estético, anteponen al primer Quijote el segundo, el de 1615, porque en él se lleva a cabo la transformación del caballero andante de viejo demente a persona sabia, poseedora de máximas virtudes: "Su ideal de la justicia planea como un águila sobre las instituciones y las leyes humanas», leemos en la página 63. «En su corazón /él/ cultiva el sentimiento más puro de justicia /.../. su visión de los ideales humanos es generosa, diáfana y sublime /.../. Sus consejos y conversaciones con Sancho /.../ inspiran el mayor respeto. En ellos se respira el espíritu y la expresión bíblicos, como cuando leemos obras de inspiración divina» ${ }^{9}$. El empeño romántico de centrarse en la pureza moral del héroe cervantino prevalece sobre todas las demás reflexiones. Por consiguiente, los críticos constatan que la novela es un repertorio de

7 Jasna Stojanović, «Prva ocena Daničarevog prevoda Don Kihota». Letopis Matice srpske, 1998, 462, 4, pp. 504-508.

8 HAIM Davičo, dr LJUBomir Nedić, op. cit., p. 63.

9 «Njegov ideal o pravdi, šestari kao orao nad ustanovama i zakonima ljudskim. U svom srcu /on/ gaji najčistiji osećaj pravičnosti /.../. /../ njegovi su pogledi na ideale ljudske plemeniti, izbistreni i uzvišeni /.../. Njegovi saveti i razgovori sa Sančom ulevaju najviše strahopošovanje. Kroz njih provejava onaj silan biblijski duh i izraz, koji nas prožima kad čitamo božanska nadahnuća». Ídem. 
preceptos y enseñanzas, idóneo para llevar una vida moral sana, y concluyen que «dar al público serbio una traducción del Quijote, es ponerle entre las manos otra Sagrada Escritura» ${ }^{10}$.

Estas consideraciones histórico-literarias en su mayor parte no son nuevas ni originales: sus ideas directrices, así como el orden de exposición y párrafos enteros están tomados del prólogo que Djordje Popović ha redactado para su traducción ${ }^{11}$. Parece obvio que en Serbia, en esta época, eran pocos los que podían rivalizar con este estudioso polifacético en cuanto al conocimiento de la biografía y la obra cervantina, dado que Popović estaba muy bien informado y se dedicaba al estudio de Cervantes con bastante rigor. No podía equipararsele ni siquiera el mismo Davičo, en cuyo ámbito de intereses hispánicos se hallaban otros autores y otras formas literarias.

En caso contrario, a un crítico de la talla de Hajim Davičo no se le podrían permitir las erratas que hemos encontrado en el artículo publicado en Bosanska vila: «El autor del Quijote», se dice allí, «/.../ vivió, sufrió y creó su obra maestra a principios del siglo XVI» (p. 63), o esta otra, que hace referencia a que el Cid luchaba contra los Arabes en el siglo XIII! Luego, aunque la mala transcripción de antróponimos castellanos no es un detalle esencial (y también se puede achacar a cualquier integrante de la cadena que va del autor a la versión impresa del texto), deja mala impresión en un trabajo firmado por un hispanista y un crítico renombrado. Tenemos en mente el ejemplo cuando, la única vez que se menciona el nombre del escritor alcalaíno en su totalidad, leemos Don Mihuel Servantes Savedra o, más adelante, cuando se menciona al Sid Kompeador (idem).

Davičo ha dado a conocer opiniones similares a las de la reseña en otra aportación, titulada "Una tarde en Jalija» ${ }^{12}$. En ella el escritor sefardí evoca su encuentro y la conversación mantenida con el poeta lírico Vojislav Ilić acerca de dos libros, en ese entonces muy en boga en Serbia: el Quijote y Gil Blas de Santillane de Le Sage. Davičo transmite al lector la interrogante que plantea el poeta: «No es en el Quijote todo aparente, como en la imaginación de un hombre enfermo, y en Gilles Blas todo real y alegre?» ${ }^{13}$. Davičo, según

10 «pružiti srpskoj publici, prevod Don Kihota, znači dati mu drugo Sveto Pismo u ruke». Ídem.

11 DJORDJE Popović, «Servantesov život i dela mu». In Migela de SeRvantesa SAVEDre, Veleumni plemić Don Kihote od Manče. Op. cit., vol. I, pp. V-XXIX

12 HAJIM S. DAVIčo, «Jedne večeri na Jaliji...». In Odbor za podizanje spomenika Vojislavu J. IlićU, Vojislavljeva spomenica. Beograd, 1895, pp. 36-39.

13 «Zar nije u Don Kihotu sve prividno, kao u mašti bolesna čoveka, a u Žil Blazu sve istinito i vedro?». Ídem, p. 37. 
confiesa él mismo, es uno de los que se acercan a la parodia cervantina con ilusión y respeto, y ven en ella el símbolo del espíritu hispano y la personificación de todas las almas justas de este mundo. En su opinión, las dos novelas citadas son antípodas: mientras Gilles Blas es un «alma de lacayo» (lakajska duša) que lo somete todo a sus bajos instintos, en el Quijote, «bajo el aspecto ridículo de este loco en apariencia, late un corazón heroico, que, tal una torrente, corre hacia un objetivo noble: defender a los débiles, castigar a los malvados, aniquilar a los depravados, y hacer justicia con espada y voluntad en todas partes. Es la encarnación de todas las virtudes. El honor, la justicia y la ilusión consumen su cuerpo y su alma» ${ }^{14}$.

Por otra parte, como sugiere el título, el encuentro de los dos amigos es motivo para evocar el pasado y el presente de Jalija, la judería belgradense situada en la orilla del Danubio. Davičo, hombre maduro, contrapone sus recuerdos de infancia a la decrepitud actual de su barrio natal, confesándole a Ilić: «Yo amaba este barrio mientras en él flotaba el espíritu de Don Quijote, y ahora lo tengo lejos del corazón porque en él se descompone el muladar de Gilles Blas» ${ }^{15}$. Como ha subrayado Krinka Vidaković-Petrov, Don Quijote se puede entender aquí como metáfora del propio Davičo que, por un lado, quería superar el atraso y el estancamiento de su mundo sefardí, y, por el otro, conservar por su propia labor lo más valioso de su tradición ${ }^{16}$.

Por último, más detalles sobre la noción que tenía Davičo del Quijote nos ofrece el breve texto introductorio para su traducción del entremés cervantino del «Retablo de las maravillas» ${ }^{17}$. Con su aportación Davičo ha contribuido al tercer centenario de la publicación de la primera parte del Quijote, e informado a los lectores de Delo sobre este aniversario. Sin embargo, dice que «se han cumplido justo trescientos años desde que, por primera vez, vio la luz el genial libro de Miguel de Cervantes Saavedra», refiriéndose sólo a la primera parte ${ }^{18}$. Con este motivo recordó, de manera harto pa-

\footnotetext{
14 «pod smešnim ruhom ovoga prividno alosanog viteza, bije junačko srce, koje stremi kao bujica, uzvišenoj meti: da štiti slabe, kazni hulje, razmoždi zlikovca, i mačem i voljom vrši svuda pravdu. U njemu su oličene sve vrline. Čast, pravda i oduševljenje, sažižu njegovo telo i njegovu dušu». Ídem, p. 38.

15 «Ja sam voleo ovaj kraj, dok je u njemu lebdeo duh Don Kihota, sad mi je otpao od srca, jer u njemu uskišnjava Žil Blazovo bunjište». Ídem, p. 37.

16 KRINKa Vidaković-PETROv, Kultura španskih Jevreja na jugoslovenskom tlu. XVI-XX vek. Svjetlost, Sarajevo, 1986, p. 113.

17 HaJim Davičo: «Servantesova proslava». Delo, 1905, 36, pp. 233-234 y MIGUEL DE SERVANTES SAAVEDRA, "Opsenarije». Ídem, pp. 234-245.

18 "navršilo ravno 300 godina, od kako je prvi put 1605 godine ugledala sveta djenijalna knjiga Don Miguela de Servantesa Saavedra». Ídem, p. 233.
} 
tética, el antiguo esplendor del imperio español, comparándolo con su decadencia a principios del siglo xx y concluyendo que le queda sólo una consolación: el ser la patria de Cervantes. Al final Davičo anotaba un testimonio interesante sobre cómo se tenía que haber conmemorado este aniversario cervantino en Serbia: «La dirección del Teatro nacional serbio tuvo la feliz y original idea de eternizar este año en su repertorio el Quijote. El hecho de no haber podido realizar esta idea, no es culpa suya, sino del caso que no existe drama que merece llevar este nombre, como le ha confirmado estos días el famoso escritor dramático español don José Echegaray al autor de estas líneas» ${ }^{19}$. Se trata, probablemente, de una iniciativa del propio Davičo, que intentaba así juntar sus dos aficiones - la que tenía por la prosa cervantina y por el teatro-. En todo caso, no carece de interés el dato de que Davičo, judío español de la pequeña Serbia, sostenía correspondencia con Echegaray, premio Nobel de literatura.

La labor traductora de Davičo merece atención particular. Aunque en el breve artículo mencionado («Conmemoración cervantina») anunciaba la intención de verter al serbio una novela ejemplar, no ha realizado ninguna traducción de un texto cervantino en prosa. No obstante, fue él quien inició la traducción de las obras dramáticas del gran alcalaíno, publicando en 1905, en las revistas belgradenses Nova iskra y Delo los entremeses del «Juez de los divorcios» y del «Retablo de las maravillas» ${ }^{20}$. Tenemos que añadir que mucho tiempo después, incluso hasta los años sesenta del siglo veinte, no tuvo seguidores en este campo.

Es en el ámbito del teatro donde este crítico y traductor experimentado se movía con más soltura. En su versión de los entremeses se nota en seguida la habilidad de un buen conocedor de la escena que sabía adaptar la oración al diálogo escénico de manera que parezca ligera, natural y eficaz. Es indudable que sus conocimientos de español eran buenos y que podía solucionar sin mayor dificultad incluso los giros más complicados del idioma clásico y percibir los matices en el habla de los personajes.

Subrayemos de entrada que estas dos traducciones en realidad son adaptaciones. Es patente sobre todo en el «Retablo», donde el

\footnotetext{
19 «Uprava srpskog narodnog pozorišta imala je srećnu i originalnu misao, da ove godine ovekoveči u svom repertoaru 'Don Kihota'. Što još nije uspela da tu misao privede $\mathrm{u}$ delo, nije krivica do nje, već do toga što nema drame, koja bi bila dostojna tog imena, kao što je to javio ovih dana slavni španski dramski pisac Don Hoze Ečegaraj, potpisatome». Ídem, pp. 233-234.

20 "Sudija za bračne parnice. Dramski intermeco od M. Servantesa». Traducción del español H. S. DAvičo, Nova iskra, 1905, 5, pp. 145-149; "Opsenarije. Medjučin Miguela de Servantesa Saavedre". Traducción del español H. S. Davičo. Delo, 1905, XXXVI/2, pp. 234-235.
} 
alejamiento del original es bastante grande. De hecho, el traductor aplica el mismo procedimiento en los dos textos -adapta el entremés a la representación teatral-. Prescindiendo de su literalidad, simplifica, acorta o simplemente elimina muchas expresiones de las lingüísticamente más complicadas, así como varias alusiones y juegos de palabras. Aunque la naturalidad del diálogo como objetivo básico justificaba los cambios en algunas ocasiones, nos parece que Davičo se alejaba con demasiada frecuencia y sin necesidad evidente del original. Por eso los lectores serbios no han podido enterarse de numerosas alusiones a fenómenos y costumbres contemporáneos de Cervantes. Generalizando, se puede decir que la versión serbia de los dos entremeses significa una simplificación considerable respecto al mensaje original del autor. Destaquemos en el mismo orden que la exactitud material de la traducción, aunque satisfactoria, no es total. Además de errores en la traducción de palabras y expresiones, al traductor a veces se le ha colado alguna solución literal («no ha salido de los límites de la razón» —nije prekoračila granice razloga- ${ }^{21}$ ). En cuanto a las palabras culturales (según la terminología de Peter Newmark ${ }^{22}$ ), destacamos dos: el sintagma "cristiano viejo», que Davičo traduce correctamente como rodjen hrišćanin ("Sudija», p. 148) y ovejan hrišćanin («Opsenarije», p. 241), y también el sustantivo «doña», que convierte en dona, en vez de transcribirlo sencillamente, conservando su sabor castellano (como ha hecho Daničar en su traducción del Quijote; "Sudija», 148), etc. El mismo «retablo de las maravillas» ha sido traducido como opsenarije (título), opsenarnica (pp. 236, 239), dečje pozoriste (235), čudotvorne slike (238) o sólo slike (225).

No obstante, el resultado final es positivo. El tono general de las dos piezas es adecuado, la breve trama ha sido reproducida con éxito, la caracterización de los personajes es fiel, y los diálogos animados y pintorescos. El humor también es eficaz y alegre. Davičo consigue trasponer en su versión, ayudándose de equivalentes serbios, el amplio repertorio de modismos y exclamaciones cervantinos (votos, juramentos...), de juegos de palabras y refranes, que confieren un aroma cómico-popular a estas piezas jocosas. Aducimos a continuación algunos ejemplos.

$\mathrm{Al}$ principio del "Juez de los divorcios», al dirigirse el Vejete a su joven esposa Mariana, Davičo ha conseguido calcar en serbio la figura etimológica, uno de los recursos estilísticos más utilizados por Cervantes:

\footnotetext{
21 «Sudija za bračne parnice». Op. cit., p. 147.

22 Peter Newmark, Manual de traducción. Madrid, Cátedra, 1995, 364 pp.
} 
«VEJETE: /.../ habla paso, por la pasión que Dios pasó /.../ (pp. 97-98) ${ }^{23}$. «ČıčicA: /.../ Muči muka radi sto ih je Gospod na krstu mučio» (p. 145).

El refrán serbio al que recurre Davičo en la siguiente oración equivale al español y cuadra muy bien en el contexto:

"MARIANA: Cedacico nuevo, tres días en estaca» (Ídem, 101).

«MARIJANA: Novo sito o klinu visi...ali samo tri dana!» (146).

O el modismo «nacer en las malvas» que el traductor ha entendido y traducido acertadamente:

«JUAN: No nacimos acá en las malvas, señor Pedro Capacho» («Retablo de las maravillas", p. 222).

«HuAN: Nismo se ni mi na bunjištu rodili, gospodine Pedro Kapačo» («Opsenarije», 238).

En algunos fragmentos del «Retablo de las maravillas» Davičo consigue, valiéndose de giros coloquiales, reproducir los parlamentos cómicos del alcalde Benito Repollo:

«BENITO: ¡Téngase, cuerpo de tal conmigo! ¡Bueno sería que, en lugar de habernos venido a holgar, quedásemos aquí hechos plasta! ¡Téngase, señor Sansón, pesia a mis males, que se lo ruegan buenos!» (p. 227).

«BENITO: Grom i pako, stante! Lepo bi nam išlo. Mi došli ovde da prodjumbusimo, a ovaj hoće da nas izgnjavi kao pitu. Stante, stari Simeone, sto mu muka! Zar ne vidite da vas čestiti gradjani mole?» (p. 240).

«BENITO: /.../ Señor Autor, o salgan figuras más apacibles, o aquí nos contentamos con las vistas, y Dios le guíe, y no pare más en el pueblo un momento" (Ídem, 231).

«BENITO: A sad nam izvedite miroljubivije zverke, ili ćemo se zadovoljiti ovim što smo dosad videli i nećemo tražiti ništa više, a vi kako vas Bog uči, hvatajte maglu i za živu glavu da niste više amo došli!» (Ídem, 242).

Como se puede ver, los diálogos de Davičo son ágiles y dinámicos, muy parecidos a los de Cervantes. El idioma utilizado es llano y libre, muy cercano al lenguaje coloquial y lleno de palabras de origen turco (srčak, šajak, aršin, mušabak, džemadane, ućelepiriti, esnaf, vajdica, amalin, konagdžija, na tehnane), mientras su leve tonalidad arcaizante le confiere un encanto particular para el lector contemporáneo.

Conocido por los contemporáneos por un privilegio del cual a finales del siglo XIX y a principios del XX podían enorgullecerse muy pocos serbios - el conocimiento de la lengua española, así como una

23 Todas las citas de los entremeses, en castellano, han sido tomadas de la edición preparada por Nicholas SPADACCINI. Madrid, Cátedra, 1983. 
vasta cultura literaria-, el sefardí Hajim Davičo supo aprovechar esta ventaja con éxito, obrando, en cuanto a Cervantes, en dos direcciones principales - la labor traductora y la crítica-.

No cabe duda alguna que Davičo representa la fase inicial de la recepción del escritor español en nuestra cultura. Fue el primero en descubrir a los serbios los textos dramáticos cervantinos: con un certero sentimiento dramático, supo escoger en su obra teatral lo más valioso y, entre ocho entremeses, traducir dos, estimados como los mejores.

Su opinión, expresada en la reseña firmada junto con dr Ljubomir Nedić, contribuyó a que en 1895-96 viese la luz la primera traducción integral del Quijote en idioma serbio. No descartamos la posibilidad que este hispanista renombrado, según muestran varios indicios, asistiera de cerca a la traducción de la novela, como una especie de consultor lingüístico de Daničar, tarea complicada para la que, sin embargo, poseía suficientes conocimientos y habilidad.

Por lo que toca a sus aportaciones críticas sobre la parodia cervantina, subrayemos que Davičo, visto desde la actualidad, era un amateur. Sus consideraciones no son nuevas y no van más allá de la idealización romántica de la figura del caballero manchego. Además, Davičo no era filólogo, ni historiador de la literatura, por lo que se nos aparece como alguien que no poseía suficientes conocimientos en el campo de la literatura española áurea. No obstante, y a pesar de todo, está claro que la cultura serbia, en los últimos decenios del siglo XIX y en los primeros del XX, echaba de menos a un hispanista así, con lo que el papel de Davičo reviste más importancia aún.

JASNA STOJANOVIĆ

Universidad de Belgrado, Yugoslavia

\section{BIBLIOGRAFÍA}

Fuentes

HaJim S. DAvičo: «Jedne večeri na Jaliji». In Odbor za podizanje spomenika VoJISLAVU J. ILIćU: Vojislavljeva spomenica. Beograd, 1895, pp. 36-39.

HaJim Davičo, dr LJUbomir Nedić: "O srpskom prevodu Don Kihota». Bosanska vila, 1896,4 , pp. $62-63$

«Sudija za bračne parnice». Dramski intermeco od M. Servantesa. Preveo sa spanskog H. S. DAvičo: Nova iskra, 1905, 5, pp. 145-149.

HaJim Davičo: "Servantesova proslava». Delo, 1905, XXXVI/2, pp. 233-234.

«Opsenarije. Medjučin Miguela de Servantesa Saavedre». Preveo sa španskog H. S. DAVIčo: Ídem, pp. 234-235. 
Cervantes, Miguel de: Entremeses. Edición de Nicholas Spadaccini. Madrid, Cátedra, 1983, $275 \mathrm{pp}$.

\section{Estudios}

DAVID A. ALKALAJ: «Haim S. Davičo kao pozorišni kritičar». Pregled, 1930, 73, pp. 11-15.

dr Mihailo B. MilošEvić: "Hajim Davičo (1854-1918)». Jevrejski almanah za 1965 67, Savez jevrejskih opština Jugoslavije, 1967, pp. 129-135.

KRINKA VIDAKOVIĆ-PETROV: Kultura španskih Jevreja na jugoslovenskom tlu. XVI-XX vek. Svjetlost, Sarajevo, 1990, $366 \mathrm{p}$.

Milica MiHaIlović: «Dve stotine godina porodice Hajim-Davičo u Beogradu». Zbornik Jevrejskog istorijskog muzeja, vol. 6. Beograd, 1992, pp. 249-276.

Petar VolK: Pozorišni život u Srbiji, 1835-1944. FDU Institut, Beograd, 1992, 570 pp.

PREDRAg Palavestra: Jevrejski pisci u srpskoj književnosti. Institut za književnost i umetnost. Beograd, 1998, 237 pp.

JaSna StoJAnović: "Prva ocena Daničarevog prevoda Servantesovog Don Kihota». Letopis Matice srpske, 1998, 462, 4, pp. 504-508. 